\title{
Associations between exhaust and non-exhaust related components of particulate matter and stroke incidence by stroke subtype in South London.
}

Siobhan Crichton ${ }^{1}$, Benjamin Barratt ${ }^{2,3}$, Anastassia Spiridou ${ }^{3}$, Uy Hoang ${ }^{1,3}$, Shao Fen Liang ${ }^{1,3}$, Yevgeniya Kovalchuk ${ }^{5}$, Sean D Beevers ${ }^{2}$, Frank Kelly ${ }^{2,3}$, Brendan Delaney ${ }^{1,3}$, Charles DA Wolfe ${ }^{1}$ 3,4

1. Division of Health and Social Care Research, King's College London, London, UK;

2. Analytical and Environmental Sciences Division and MRC-PHE Centre for Environment and Health, King's College London, UK;

3. NIHR Biomedical Research Centre, Guy's \& St. Thomas' NHS Foundation Trust and King's College London, London, UK;

4. National Institute of Health Research Collaboration for Leadership in Applied Health Research and Care (CLAHRC) South London, London, UK;

5. NIHR Biomedical Research Centre for Mental Health \& Biomedical Research Unit for Dementia, King's College London, UK.

\section{Acknowledgements}

The research was funded/supported by the National Institute for Health Research (NIHR) Biomedical Research Centre based at Guy's and St Thomas' NHS Foundation Trust and King's College London, and the NIHR Collaboration for Leadership in Applied Health Research and Care South London at King's College Hospital NHS Foundation Trust. The views expressed are those of the authors and not necessarily those of the NHS, the NIHR or the Department of Health.

\section{Conflicts of interest}

All the authors declare they have no competing interests 


\section{Abstract}

Introduction:

Airborne particulate matter (PM) consists of particles from diverse sources, including vehicle exhausts. Associations between short-term PM changes and ischaemic stroke incidence have been shown. Long-term cumulative exposures over several months, or even years, are less well studied; few studies examined ischaemic subtypes or source of PM. This study combines a high resolution urban air quality model with a population-based stroke register to explore associations between long-term exposure to PM and stroke incidence.

\section{Method:}

Data from the South London Stroke Register from 2005-2012 were included. Poisson regression explored association between stroke incidence and long-term (averaged across the study period) exposure to $\mathrm{PM}_{2.5}\left(\mathrm{PM}<2.5 \mu \mathrm{m}\right.$ diameter) and $\mathrm{PM}_{10}(\mathrm{PM}<10 \mu \mathrm{m})$, nitric oxide, nitrogen dioxide, nitrogen oxides and ozone, at the output area level (average population=309). Estimates were standardised for age and sex and adjusted for socioeconomic deprivation. Models were stratified for ischaemic and haemorrhagic strokes and further broken down by Oxford Community Stroke Project classification.

\section{Results:}

1800 strokes were recorded (incidence $=42.6 / 100,000$ person-years). No associations were observed between PM and overall ischaemic or haemorrhagic incidence. For an interquartile range increase in $\mathrm{PM}_{2.5}$, there was a $23 \%$ increase in incidence (Incidence rate ratio=1.23 (95\% Cl:1.03-1.44)) of total anterior circulation infarcts (TACl) and $20 \%$ increase for $\mathrm{PM}_{2.5}$ from exhausts (1.20(1.01-1.41)). There were similar associations with $\mathrm{PM}_{10}$, overall (1.21(1.011.44)) and from exhausts (1.20(1.01-1.41)). TACl incidence was not associated with nonexhaust sources. There were no associations with other subtypes or pollutants.

\section{Conclusion:}

Outdoor air pollution, particularly that arising from vehicle exhausts, may increase risk of TACI but not other subtypes. 


\section{Background}

Stroke is a leading and growing cause of mortality and morbidity worldwide. In 2010 it is estimated 17 million first strokes occurred, an increase of $68 \%$ since 1990 and there were 33 million stroke survivors worldwide[1]. The contribution of outdoor air pollution on risk of stroke has been increasingly studied in recent years [2-14].

Particulate matter (PM) comprises a collection of particles from diverse sources, the proportion of each dependent on weather conditions, local geography and proximity to emission source. Epidemiological and toxicological studies have shown varying types and degrees of health effects associated with particulate matter, suggesting a role for both their chemical composition and physical properties [15]. Increasingly detailed urban air pollution models are now able to separate PM into source-related components [16], providing an opportunity to carry out more in depth epidemiological studies into associations between health impacts and PM components.

Several studies have found associations between short-term changes, or spikes, in air pollution and risk of stroke $[5,6,10,11,13,17,18]$. The pollutants considered in these studies varied, but many have looked at the effect of particulate matter, $\mathrm{PM}_{10}$ and/or $\mathrm{PM}_{2.5}$ (particulate matter below $10 \mu \mathrm{m}$ and $2.5 \mu \mathrm{m}$ in diameter respectively). A recent meta-analysis of 19 studies reporting the short-term effects of changes in particulate matter found $\mathrm{PM}_{10}$, but not $\mathrm{PM}_{2.5}$, was associated with an increase in risk of ischaemic stroke but no association was found with haemorrhagic strokes [14].

There has been less focus on the effect of long-term exposure to pollutants, i.e. the concentration averaged over months or even years, usually measured at place of residence. Some existing studies have found no associations with risk of stroke $[3,7,8,12]$ but $\mathrm{PM}_{10}$ and $\mathrm{NO}_{2}$ were associated with increased risk of death from stroke $[9,12]$. The European ESCAPE cohort study found a $5-\mu \mathrm{g} / \mathrm{m} 3$ increase in annual $\mathrm{PM}_{2.5}$ exposure was associated with $19 \%$ increased risk of incident stroke, with similar findings for $\mathrm{PM}_{10}$ [19]. A small number of studies have looked in detail at risk of specific ischaemic stroke subtypes $[2,7,11,18,20]$. One study of patients admitted to a stroke unit in Italy looked at short-term exposure to a number of pollutants and risk of ischaemic stroke subtypes categorised using the TOAST and OCSP 
classifications. $\mathrm{PM}_{10}$ was associated with increased risk of lacunar anterior circulatory syndrome in all participants, and total anterior circulator syndrome in males only [18]. Other studies have found associations between short-term exposure to pollutants and increased risk of strokes due to large artery atherosclerosis[2, 11, 20] and small vessel occlusion [11, 20].

Furthermore, meta-analysis by the METASTROKE collaboration and review of Genome Wide Association Studies (GWAS) for ischaemic stroke have found that the majority of genetic variant associations were specific to a stroke subtype, suggesting that different stroke subtypes have different risk factor profiles and pathophysiological mechanisms [21, 22].

This study combines a high resolution urban air quality model with a detailed stroke register to investigate the effect of long-term exposure to a range of PM components on stroke incidence, stratified by stroke subtype to glean more information aetiology in relation to exposure. It is an update to a previous study [7], which found no association between longterm exposure to air pollution risk of any ischaemic subtype, but only considered $\mathrm{NO}_{2}$ and $\mathrm{PM}_{10}$ as pollutant metrics.

\section{Methods}

\section{Case identification}

Information on first ever stroke was derived from the South London Stroke Register (SLSR), an ongoing population-based study of incidence and outcome. The SLSR has been prospectively recording all first-ever stroke in a geographically defined area of South London since 1995. The detailed methods of notification of patients and data collection have been described previously [23]. In brief, patients were identified by register nurses and doctors using multiple sources of notification and recruited to the register as soon as possible after stroke onset. The World Health Organization criteria were used to define stroke [24]. Pathological subtype of stroke was classified as cerebral infarction, primary intracerebral haemorrhage $(\mathrm{PICH})$, subarachnoid haemorrhage $(\mathrm{SAH})$, or unknown. Infarcts were further defined using the Oxford Community Stroke Project classification definitions as total anterior circulation infarct (TACl), partial anterior circulation infarct (PACl), lacunar infarct (LACI), 
posterior circulation infarct ( $\mathrm{POCl})$, or infarct unspecified. In this study data were included on all strokes recorded between 2005 and 2012, the period during which pollution data were available.

\section{Derivation of observed and expected incidence rates}

At the time of the 2011 census the SLSR source population consisted of 357,308 individuals of which $56 \%$ were of white ethnicity, $25 \%$ Black (14\% Black African, $7 \%$ black Caribbean, $4 \%$ Black Other), 6\% Asian and 12\% other ethnic group. Between 2001 and 2011 the population of the SLSR area increased by $15.3 \%$, with the largest increases occurring among 45 to 59 year olds (44\% increase), Asian (51\% increase) and other ethnic groups (232\% increase).

In this study, census output areas (OAs) were used as the unit of analysis. Each OAs includes a recommended minimum of 125 households with an absolute minimum or 40 households or 100 usual residents. In 2011 each output area included an average of 309 residents [25]. Output areas are the smallest geographical unit for which population estimates broken down by gender and age (in 5 year bands) are available in both the 2001 and 2011 census. In 2001 there were 1099 OAs and in 2011 there were 1148 OAs in the SLSR area. Of these 1049 were the same at both time points. Fourteen 2001 census areas were merged with one or more other areas to give 42011 OAs, while 36 were split into 2 or more new areas corresponding to 952011 OAs. In order to combine population data from the 2001 and 2011 census, 2011 OAs which were a result of 2001 OAs being split were merged in the 2011 data (36 2001 OAs were split into 952011 OAs) while 2001 OAs which were merged in the 2011 census were merged in the 2001 data. Consequently. a total of 1089 areas were included in the analysis.

To derive the population at risk in each year of the study, the rate of change in population size in each age group in males and females within an output area was assumed to be linear and estimated using the data from the 2001 and 2011 censuses. The expected number of strokes in each OA for each year, standardised for age and sex were then derived and summed to give the total number of expected strokes in each output area over the total study period.

\section{Air pollution model}


Air pollution concentrations were derived using the KCLurban model developed at King's College London as part of the NERC/MRC/SRC/DEFRA/DoH Traffic Pollution and Health in London project ('Traffic'). KCLurban model provided annual mean $\mathrm{NO}_{\mathrm{x}}, \mathrm{NO}_{2}, \mathrm{O}_{3}, \mathrm{PM}_{10}$ and $\mathrm{PM}_{2.5}$ concentrations at the geographical centre of each post code within the study area, for all sources and separately for traffic exhaust and non-exhaust sources. Annual mean concentrations were produced for the years 2005 to 2012.

The KCLurban model used a kernel modelling technique, based upon $\operatorname{ADMS}[26,27]$, to describe the initial dispersion from each emissions source. The contribution from each source was aggregated onto a fixed $20 \mathrm{~m} \times 20 \mathrm{~m}$ grid across London. The model used emissions from the London Atmospheric Emissions Inventory (LAEI)[28] . Inventory exhaust emissions factors were combined with UK specific roadside measurements[29]. Non-exhaust emissions were based upon the work of Harrison[30] ${ }^{5}$.

Sources within the model included: road transport (exhaust and non-exhaust), large regulated industrial processes, small regulated industrial processes, large boiler plant, gas heating (domestic and industrial-commercial), oil combustion sources (domestic and commercial), coal combustion sources (domestic and commercial), agricultural and natural sources, rail, ships, airports and others (sewage plant etc). In modelling the emissions from large industrial processes use was made of emissions data and stack conditions (height, temperature, volume flow rate) for each source.

The KCLurban model is well established for use in public health research [31-33] and has been submitted to the UK Model Inter-comparison Exercise, run by King's on behalf of DEFRA (http://uk-air.defra.gov.uk/library/reports?report_id=777). The model's performance was assessed against the long-term fixed air quality monitoring sites that form the London Air Quality Network (http://www.londonair.org.uk). Additional information and validation of the model is available in Supplement 1.

\section{Derivation of long-term air pollution concentrations}

To obtain average pollution concentrations for the analysis, a weighted average was derived. Population counts per postcode in the study area at the time of the 2011 census were used 
to weight the pollution concentration at each postcode and an average calculated within each output area in the study. An average across years was then taken to provide an estimate of average pollution levels in each OA across the study period.

\section{Socio-economic deprivation}

The Income Domain of the 2007 Index of Multiple Deprivation (IMD) was used as a measure of socioeconomic deprivation. This is a standard index used by government agencies in England and Wales and is available at the lower super-output area level (LSOA). Each LSOA typically contains between 4 and 6 OAs with the same score assigned to all OAs within a LSOA.

\section{Database}

A relational database was developed to link stroke data from the SLSR with air pollution data. Stroke patient information includes socio-demographic details and a number of stroke related clinical observations. For example, vital characteristics, risk factors and co-morbidities, stroke subtype classification, stroke severity and outcomes, etc.

Air pollution information is stored in the form of annual concentrations for a number of pollutants at postcode resolution. Pollutants included in the database are: nitric oxide (NO), nitrogen dioxide $\left(\mathrm{NO}_{2}\right)$, nitrogen oxides $(\mathrm{NOx})$, ozone $\left(\mathrm{O}_{3}\right)$; particulate matter below $10 \mu \mathrm{m}$ $\left(\mathrm{PM}_{10}\right)$ and particulate matter below $2.5 \mu \mathrm{m}\left(\mathrm{PM}_{2.5}\right)$ with the latter two further broken down into exhaust and non-exhaust components

Patient and air pollution data are linked using postcodes. Storing data at postcode resolution provides flexibility in the geographical level used for analysis depending on requirements.

\section{Statistical Analysis}

Poisson regression models were used with air pollutant concentrations and the IMD income scores included as continuous variables and the logarithm of expected counts as the offset. Robust standard errors were calculated to take account of any over dispersion.

We examined all strokes combined and ischemic strokes, PICH and SAHs separately. We then repeated the analysis within each of the ischemic stroke subtypes (TACl, $\mathrm{PACl}, \mathrm{POCl}$ and $\mathrm{LACl})$. 
As some of the pollutants were highly correlated with each other, the effects of each pollutant were examined in separate analyses.

Results are expressed as incident rate ratios (IRR) with 95\% confidence intervals (Cl's), representing the rate ratio for a one interquartile range (IQR) increase in the level of the pollutant. When exploring the associations across multiple pollutants and subtypes using a series of hypothesis tests is likely to result in false positive results. While adjustments to $p$ values for multiple comparisons exist, as well as pollutants being highly correlated (e.g $\mathrm{PM}_{10}$ and $\mathrm{PM}_{2.5}$ ) some are a combination of others (e.g. $\mathrm{PM}_{10}$ comprises of the exhaust and nonexhaust components) and so separate hypothesis tests would not be independent and standard methods of adjustment for multiple comparisons not valid.

Further, the aim of this study was to explore the relationship between pollutants and incidence across several different subtypes and so $p$-values are not reported. The estimated IRRs instead provide an indication of the pollutants which are likely to have the greatest effect on stroke incidence.

Analysis was conducted using STATA 13MP.

\section{$\underline{\text { Results }}$}

In total 1800 incident strokes were recorded. The overall crude incidence rate was 42.6 per 100,000 person years. An average of 1.65 strokes were recorded per output area, with a maximum of 8 within a single area. The average age at the time of stroke was 68.8 years (standard deviation 15.8) and just over half (52.3\%) were in males (Table 1). Three quarters of all strokes were recorded as ischaemic stroke, with the most common ischaemic subtype being PACl (29.6\% of all cases) followed by LACI (23.2\%). The distribution of each of the pollutants included in the study are displayed in Figure 1.

None of the pollutants were associated with overall, ischaemic or haemorrhagic stroke incidence (Table 2). However, $\mathrm{PM}_{10}$ and $\mathrm{PM}_{2.5}$ were associated with increased risk of TACls (Table 3). For a one interquartile range increase in $\mathrm{PM}_{10}$, there was a $21 \%$ increase in stroke incidence (IRR $1.21(95 \% \mathrm{Cl} 1.01-1.44))$ and a IQR increase in $\mathrm{PM}_{10}$ from exhausts associated with a $20 \%$ increase in TACl incidence (IRR $1.20(95 \% \mathrm{Cl} 1.01-1.41)$ ). There were similar 
associations with $\mathrm{PM}_{2.5}$ overall (IRR $1.23\left(95 \% \mathrm{Cl}\right.$ 1.03-1.44)) and $\mathrm{PM}_{2.5}$ from exhausts (IRR 1.20 $(95 \% \mathrm{Cl} 1.01-1.41))$. Risk of $\mathrm{TACl}$ was not associated with $\mathrm{PM}_{10}$ or $\mathrm{PM}_{2.5}$ from non-exhaust sources and there were no associations between any other pollutants and subtypes (Table 4).

\section{$\underline{\text { Discussion }}$}

This study looked at the association between air pollutants and incidence of stroke. The level of detail in the stroke and air pollution database allowed this association to be explored split across a large number of pollutants and stroke subtypes. While no associations were observed overall, or for ischaemic or haemorrhagic strokes, when ischaemic strokes were broken down by subtype, particulate matter was associated with increased risk of total anterior circulatory infarcts (TACl). The incidence rate ratio for $\mathrm{PM}_{2.5}$ was similar to that of $\mathrm{PM}_{10}$, and was only slightly higher for exhaust compared to non-exhaust related components of $\mathrm{PM}_{10}$ and $\mathrm{PM}_{2.5}$.

The lack of association observed between long-term exposure and risk of all, ischaemic or haemorrhagic stroke is in line with findings from previous studies $[3,4,8]$. Only one study of the long-term effects found a significant increased risk of haemorrhagic stroke associated with long-term exposure to $\mathrm{NO}_{2}$ in Japan [12].

Few studies have looked at associations between pollutants and specific types of stroke. Corea et al examined the associations between multiple pollutants $\left(\mathrm{PM}_{10}\right.$, carbon monoxide, nitric oxide, nitrogen oxide, sulphur dioxide, benzene and ozone) and hospitalisation for acute stroke, broken down by subtype according to the Oxford Community Stroke Project (OCSP) and Trial of Org Acute Stroke treatment (TOAST) classifications. They found an increased risk of lacunar anterior circulatory syndrome $(L A C l)$ associated with $\mathrm{PM}_{10}$ levels on the day of admission and an increased risk of $\mathrm{TACl}$ in males but not females. There were no significant associations found when broken down by TOAST classification. Other studies have found associations between short-term exposure to pollutants and found increased risk of strokes due to large artery atherosclerosis $[2,11,20]$ and small vessel occlusion $[11,20]$.

Only one study has looked at the long-term effect of exposure to pollutants and risk of stroke by ischaemic stroke subtype [7]. Data from the South London Stroke register from 1995-2007 was used but no associations were found between $\mathrm{PM}_{10}$ or $\mathrm{NO}_{2}$ and risk of any ischaemic 
subtype. In the current study data were available for a number of new pollutants, including particulate matter according to source as a result of advancements in the underlying model used to generate the spatial pollutant database. Increased risk of TACls was associated with $\mathrm{PM}_{10}$ and $\mathrm{PM}_{2.5}$ concentrations. The association was significant for particulate matter arising from exhaust, but not non-exhaust.

\section{Possible mechanism}

Particulate material has been shown to impair the respiratory and cardiovascular system through a combination of autonomic, haemostatic, inflammatory, and vascular endothelial disturbances with consequent changes in cardiac and vascular function [11, 14]. However, the effect of exposure to particulate matter on cerebral vessels is more uncertain and the mechanism by which any effect on cerebral vascular disease is mediated is yet to be elucidated.

Researchers have postulated that PM's effect on ischemic stroke might be regulated by systemic inflammation and activation of the coagulation system, leading to atherosclerosis, vasoconstriction, increase of fibrinogen and acceleration the formation of acute thrombus [14].

The association between particulate pollution and TACl strokes shown in this study suggests that mechanism involving large-artery atherosclerosis, altered haemodynamics and/or vascular dysfunction, such as increases in blood pressure and heart rate and variability that results in disruption of a vulnerable atherosclerotic plaque with subsequent thrombosis and/or downstream embolism may be particularly important contributing factors [20].

\section{Strengths and limitations}

To the best of our knowledge this is the first study which has looked at the long-term exposure to particulate matter from exhausts and non-exhausts, and the risk of stroke, broken down by subtype. While the majority of the existing studies of short and long-term effects of air pollution use admissions to hospitals or stroke units to identify cases, this study used data from a population based register collecting data on all strokes within a defined area. It is 
estimated that the completeness of case ascertainment on the register is $88 \%$ [23] and includes those not-admitted to hospital.

In this study long term exposure was defined as the average pollution concentration in the output area that the participant resided in at the time of stroke. Pollutant concentrations were available at the postcode level for each year of the study. Due to the relatively low number of strokes per year recorded by the SLSR, to explore the association between pollutants and stroke incidence it was necessary to average across postcodes within each output area and then across the study period. Pollutant levels within each output area are highly correlated from one year to the next, but it is possible some trends could be missed due to the loss of detail resulting from averaging pollutant levels. Further, no information was available on how long the participant had been resident in the area at the time of stroke or what proportion of time is spent in their home. More detailed information of day to day activities in the lead up to stroke onset would be required to enable more accurate measures of cumulative exposure over time, but would not be feasible in a cohort study such as the SLSR.

\section{Conclusion}

Outdoor air pollution, particularly that arising from vehicle exhausts, was associated with an increased risk of total anterior circulation infarcts but not with any other stroke subtype. 
Table 1: Incident stroke cases from 2005-2012 by age, sex and stroke subtype

\begin{tabular}{lc}
\hline & $\mathrm{N}(\%)$ \\
\hline Total & 1800 \\
Age, mean(sd) & $68.8(15.8)$ \\
Age & \\
$<55$ years & $364(20.2)$ \\
$55-64$ years & $300(16.7)$ \\
$65-74$ years & $396(22.0)$ \\
$75-84$ years & $465(25.8)$ \\
$>85$ years & $275(15.3)$ \\
Gender & \\
Male & $942(52.3)$ \\
Female & $858(47.7)$ \\
Subtype & \\
TACl & $189(10.5)$ \\
PACl & $532(29.6)$ \\
POCl & $196(10.9)$ \\
LACl & $417(23.2)$ \\
Infarction unspecified & $4(0.2)$ \\
PICH & $204(11.3)$ \\
SAH & $57(3.2)$ \\
Unknown/undefined & $201(11.2)$ \\
\hline
\end{tabular}

Abbreviations: $\mathrm{TACl}$, total anterior circulation infarct; $\mathrm{PACl}$, partial anterior circulation infarct; $\mathrm{LACl}$, lacunar infarct; $\mathrm{POCl}$, posterior circulation infarct; $\mathrm{PCIH}$, primary intracerebral haemorrhage; $\mathrm{SAH}$, subarachnoid haemorrhage 
Figure 1: Distribution of average pollutant concentrations within each output area

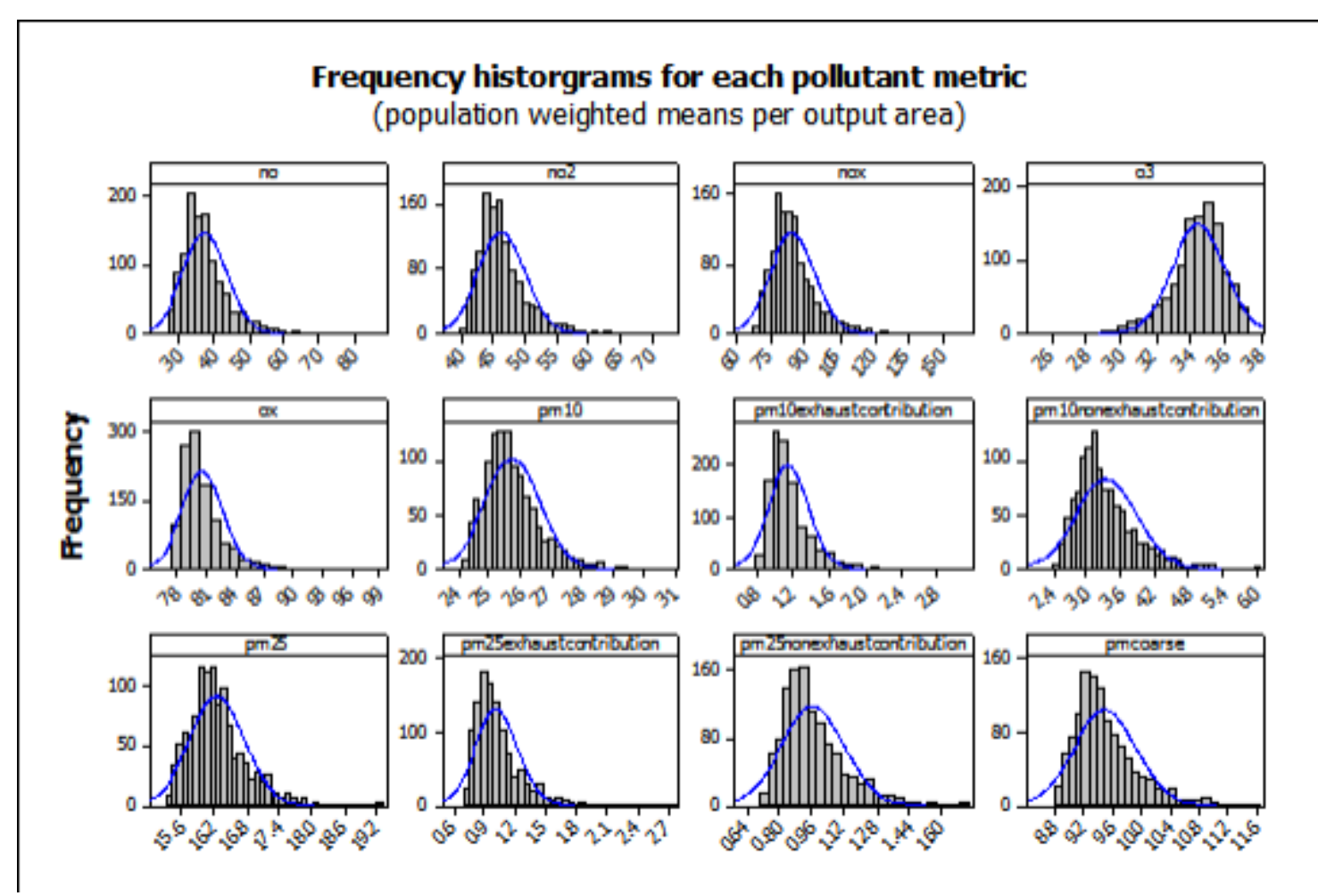

Abbreviations: $\mathrm{NO}$, nitric oxide; $\mathrm{NO}_{2}$, nitrogen dioxide; $\mathrm{NO}_{x}$, nitrogen oxides; $\mathrm{O}_{3}$, ozone; $\mathrm{PM}_{10}$, particulate matter below $10 \mu \mathrm{m}$; $\mathrm{PM} 2.5$, particulate matter below $2.5 \mu \mathrm{m}$. 
Table 2: Associations between pollutants and all stroke, ischaemic stroke, $\mathrm{PICH}$ and SAH incidence

\begin{tabular}{lcccc}
\hline & All stroke & $\begin{array}{c}\text { Ischaemic } \\
\text { strokes }\end{array}$ & PICH & SAH \\
\hline $\mathrm{N}$ & 1800 & 1338 & 204 & 57 \\
\hline Incidence & IRR (95\% CI) & IRR (95\% CI) & IRR (95\% CI) & IRR (95\% CI) \\
\hline $\mathrm{NO}$ & $0.99(0.93-1.05)$ & $0.97(0.91-1.04)$ & $0.95(0.80-1.13)$ & $1.04(0.73-1.47)$ \\
$\mathrm{NO}_{2}$ & $0.99(0.94-1.04)$ & $0.97(0.91-1.04)$ & $0.96(0.82-1.13)$ & $1.06(0.77-1.44)$ \\
$\mathrm{NO}_{x}$ & $0.99(0.94-1.05)$ & $0.97(0.91-1.04)$ & $0.96(0.81-1.13)$ & $1.05(0.76-1.44)$ \\
$\mathrm{O}_{3}$ & $1.00(0.95-1.06)$ & $1.02(0.95-1.09)$ & $1.04(0.88-1.24)$ & $0.95(0.68-1.34)$ \\
$\mathrm{Ox}$ & $0.99(0.94-1.04)$ & $0.97(0.91-1.03)$ & $0.97(0.83-1.12)$ & $1.06(0.79-1.42)$ \\
$\mathrm{PM}_{10}$ & $1.00(0.74-1.06)$ & $0.98(0.92-1.05)$ & $0.97(0.81-1.15)$ & $1.01(0.72-1.43)$ \\
$\mathrm{PM}_{10}$ exhaust & $0.99(0.93-1.04)$ & $0.97(0.90-1.04)$ & $0.94(0.79-1.12)$ & $0.90(0.64-1.27)$ \\
$\mathrm{PM}_{10}$ non-exhaust & $1.00(0.94-1.06)$ & $0.97(0.90-1.04)$ & $0.98(0.82-1.17)$ & $1.09(0.76-1.57)$ \\
$\mathrm{PM}_{2.5}$ & $1.00(0.95-1.06)$ & $0.99(0.93-1.06)$ & $0.96(0.81-1.14)$ & $0.93(0.67-1.30)$ \\
$\mathrm{PM}_{2.5}$ exhaust & $0.99(0.93-1.04)$ & $0.97(0.91-1.04)$ & $0.94(0.78-1.12)$ & $0.90(0.64-1.28)$ \\
PM $_{2.5}$ non-exhaust & $0.99(0.94-1.05)$ & $0.97(0.90-1.04)$ & $0.98(0.82-1.16)$ & $1.03(0.72-1.48)$ \\
$\mathrm{PM}_{\text {coarse }}$ & $1.00(0.94-1.05)$ & $0.97(0.91-1.04)$ & $0.98(0.83-1.16)$ & $1.10(0.76-1.56)$ \\
\hline
\end{tabular}

Abbreviations: $\mathrm{NO}$, nitric oxide; $\mathrm{NO}_{2}$, nitrogen dioxide; $\mathrm{NO}$, nitrogen oxides; $\mathrm{O}_{3}$, ozone; $\mathrm{PM}_{10}$, particulate matter below $10 \mu \mathrm{m}$; $\mathrm{PM} 2.5$, particulate matter below $2.5 \mu \mathrm{m}$. 
Table 3: Associations between pollutants and incidence of stroke broken down by aetiological subtype

\begin{tabular}{lllll}
\hline & $\mathrm{TACl}$ & $\mathrm{PACl}$ & $\mathrm{POCl}$ & $\mathrm{LACl}$ \\
\hline $\mathrm{N}$ & 189 & 532 & 196 & 417 \\
\hline Incidence & IRR (95\% CI) & IRR (95\% Cl) & IRR (95\% CI) & IRR (95\% CI) \\
$\mathrm{NO}$ & $1.15(0.97-1.36)$ & $0.93(0.83-1.05)$ & $1.00(0.80-1.25)$ & $0.93(0.82-1.05)$ \\
$\mathrm{NO}_{2}$ & $1.13(0.97-1.32)$ & $0.93(0.94-1.04)$ & $1.00(0.81-1.23)$ & $0.94(0.84-1.05)$ \\
$\mathrm{NO}_{x}$ & $1.14(0.97-1.32)$ & $0.94(0.84-1.04)$ & $1.00(0.81-1.23)$ & $0.94(0.83-1.05)$ \\
$\mathrm{O}_{3}$ & $0.85(0.71-1.00)$ & $1.06(095-1.19)$ & $1.00(0.80-1.26)$ & $1.06(0.94-1.19)$ \\
$\mathrm{Ox}$ & $1.10(0.96-1.27)$ & $0.93(0.84-1.02)$ & $0.99(0.82-1.21)$ & $0.94(0.84-1.04)$ \\
$\mathrm{PM}_{10}$ & $\mathbf{1 . 2 1 ( 1 . 0 1 - 1 . 4 4 )}$ & $0.94(0.84-1.05)$ & $0.99(0.79-1.24)$ & $0.94(0.82-1.06)$ \\
$\mathrm{PM}_{10}$ exhaust & $\mathbf{1 . 2 0 ( 1 . 0 1 - 1 . 4 1 )}$ & $0.92(0.82-1.03)$ & $1.02(0.81-1.28)$ & $0.91(0.81-1.03)$ \\
$\mathrm{PM}_{10}$ non-exhaust & $\mathbf{1 . 1 7 ( 0 . 9 8 - 1 . 3 9 )}$ & $0.94(0.84-1.05)$ & $0.96(0.77-1.20)$ & $0.92(0.81-1.05)$ \\
$\mathrm{PM}_{2.5}$ & $\mathbf{1 . 2 2 ( 1 . 0 3 - 1 . 4 4 )}$ & $0.95(0.85-1.06)$ & $1.01(0.81-1.27)$ & $0.95(0.85-1.06)$ \\
$\mathrm{PM}_{2.5}$ exhaust & $\mathbf{1 . 2 0 ( 1 . 0 1 - 1 . 4 1 )}$ & $0.92(0.82-1.04)$ & $1.02(0.81-1.28)$ & $0.91(0.81-1.03)$ \\
$\mathrm{PM}_{2.5}$ non-exhaust & $1.17(0.99-1.39)$ & $0.94(0.84-1.06)$ & $0.96(0.77-1.20)$ & $0.92(0.81-1.04)$ \\
$\mathrm{PM}_{\text {coarse }}$ & $1.05(0.98-1.29)$ & $0.94(0.84-1.05)$ & $0.96(0.77-1.20)$ & $0.93(0.82-1.05)$ \\
\hline
\end{tabular}




\section{References}

1. Feigin, V.L., et al., Global and regional burden of stroke during 1990-2010: findings from the Global Burden of Disease Study 2010. The Lancet, 2014. 383(9913): p. 245-255.

2. Henrotin, J.-B., et al., Short-term effects of ozone air pollution on ischaemic stroke occurrence: a case-crossover analysis from a 10-year population-based study in Dijon, France. Occupational and environmental medicine, 2007. 64(7): p. 439-445.

3. Johnson, J.Y., et al., A case-control study of medium-term exposure to ambient nitrogen dioxide pollution and hospitalization for stroke. BMC public health, 2013. 13(1): p. 368.

4. Johnson, J.Y., B.H. Rowe, and P.J. Villeneuve, Ecological analysis of long-term exposure to ambient air pollution and the incidence of stroke in Edmonton, Alberta, Canada. Stroke, 2010. 41(7): p. 1319-1325.

5. Leiva G, M.A., et al., A five-year study of particulate matter (PM2. 5) and cerebrovascular diseases. Environmental Pollution, 2013. 181: p. 1-6.

6. Lisabeth, L.D., et al., Ambient air pollution and risk for ischemic stroke and transient ischemic attack. Annals of neurology, 2008. 64(1): p. 53-59.

7. Maheswaran, R., et al., Outdoor air pollution, subtypes and severity of ischemic stroke-a smallarea level ecological study. International Journal of Health Geographics, 2014. 13(1): p. 23.

8. Maheswaran, R., et al., Outdoor Air Pollution and Incidence of Ischemic and Hemorrhagic Stroke A Small-Area Level Ecological Study. Stroke, 2012. 43(1): p. 22-27.

9. Maheswaran, R., et al., Impact of outdoor air pollution on survival after stroke populationbased cohort study. Stroke, 2010. 41(5): p. 869-877.

10. Qian, Y., et al., Epidemiological evidence on association between ambient air pollution and stroke mortality. Journal of epidemiology and community health, 2013: p. jech-2012-201096.

11. Wellenius, G.A., et al., Ambient air pollution and the risk of acute ischemic stroke. Archives of internal medicine, 2012. 172(3): p. 229-234.

12. Yorifuji, T., et al., Long-term exposure to traffic-related air pollution and the risk of death from hemorrhagic stroke and lung cancer in Shizuoka, Japan. Science of the Total Environment, 2013. 443: p. 397-402.

13. Yorifuji, T., E. Suzuki, and S. Kashima, Cardiovascular Emergency Hospital Visits and Hourly Changes in Air Pollution. Stroke, 2014. 45(5): p. 1264-1268.

14. Yu, X.-B., et al., Short-Term Effects of Particulate Matter on Stroke Attack: Meta-Regression and Meta-Analyses. PloS one, 2014. 9(5): p. e95682.

15. WHO, Review of evidence on health aspects of air pollution - REVIHAAP Project: Final technical report. 2013, World Health Organisation.

16. Beevers, S.D., et al., Air pollution dispersion models for human exposure predictions in London. J Expo Sci Environ Epidemiol, 2013.

17. Carlsen, H.K., et al., Ozone is associated with cardiopulmonary and stroke emergency hospital visits in Reykjavik, Iceland 2003-2009. Environmental health, 2013. 12(1): p. 28.

18. Corea, F., et al., Airborne pollutants and lacunar stroke: a case cross-over analysis on stroke unit admissions. Neurology international, 2012. 4(2).

19. Stafoggia, M., et al., Long-term exposure to ambient air pollution and incidence of cerebrovascular events: results from 11 European cohorts within the ESCAPE project. Environ Health Perspect, 2014. 122(9): p. 919-25.

20. O'Donnell, M.J., et al., Fine particulate air pollution (PM2. 5) and the risk of acute ischemic stroke. Epidemiology (Cambridge, Mass.), 2011. 22(3): p. 422.

21. Markus, H.S. and S. Bevan, Mechanisms and treatment of ischaemic stroke [mdash] insights from genetic associations. Nature Reviews Neurology, 2014. 10(12): p. 723-730. 
22. Traylor, M., et al., Genetic risk factors for ischaemic stroke and its subtypes (the METASTROKE collaboration): a meta-analysis of genome-wide association studies. The Lancet Neurology, 2012. 11(11): p. 951-962.

23. Heuschmann, P.U., et al., Ethnic group disparities in 10-year trends in stroke incidence and vascular risk factors The South London Stroke Register (SLSR). Stroke, 2008. 39(8): p. 22042210.

24. Hatano, S., Experience from a multicentre stroke register: a preliminary report. Bull World Health Organ, 1976. 54(5): p. 541-53.

25. ONS. [cited 2015 07/08/2015]; Available from: http://www.ons.gov.uk/ons/guidemethod/geography/beginner-s-guide/census/output-area--oas-/index.html.

26. CERC. ADMS 4 and Roads user guides. 2004 24/07/15; Available from: www.cerc.co.uk.

27. CERC. ADMS-Roads An Air Quality Management System User Guide. Cambridge Environmental Research Consultants Ltd, Cambridge. 2006 [cited 2012 03/01/2012]; Available from: http://www.cerc.co.uk/environmental-software/assets/data/doc userguides/CERC ADMSRoads\%20Extra3.1 User Guide.pdf.

28. (GLA), G.L.A. The London Atmospheric Emissions Inventory 2010. 2010 [cited 2015 08/01/2015]; Available from: http://data.london.gov.uk/dataset/london-atmosphericemissions-inventory-2010.

29. Carslaw, D.C., et al., Recent evidence concerning higher NO x emissions from passenger cars and light duty vehicles. Atmospheric Environment, 2011. 45(39): p. 7053-7063.

30. Harrison, R.M., et al., Estimation of the contributions of brake dust, tire wear, and resuspension to nonexhaust traffic particles derived from atmospheric measurements. Environmental science \& technology, 2012. 46(12): p. 6523-6529.

31. Halonen, J.I., et al., Is long-term exposure to traffic pollution associated with mortality? A small-area study in London. Environmental Pollution, 2015.

32. Kelly, F., et al., The impact of the congestion charging scheme on air quality in London. Part 1. Emissions modeling and analysis of air pollution measurements. Research report (Health Effects Institute), 2011(155): p. 5-71.

33. Tonne, C., et al., Traffic-related air pollution in relation to cognitive function in older adults. Epidemiology (Cambridge, Mass.), 2014. 25(5): p. 674. 